\title{
Microstructure and crystal structure of an equimolar Mg-Ti alloy processed by Simoloyer high-energy ball mill
}

Kasonde Maweja $^{\mathrm{a}, *}$, Maje Phasha ${ }^{\mathrm{a}}$, Nic van der Berg ${ }^{\mathrm{b}}$

${ }^{a}$ The Council for Scientific and Industrial Research, CSIR, Metals and Metals

Processes, Materials Science and Manufacturing, P.O. Box 395, Pretoria 0001, South Africa

${ }^{\mathrm{b}}$ Department of Physics, University of Pretoria, Pretoria 0002, South Africa

${ }^{*}$ Corresponding author: K. Maweja

Email: mawejak@yahoo.fr

Tel: +27833650952 


\begin{abstract}
The solid solubility of 50-50 at.\% Mg-Ti powder mixtures was achieved by means of high energy ball milling in a Simoloyer equipment. XRD and HRTEM analyses revealed the existence of FCC and $\mathrm{BCC}$ matrix of Ti solid solution in $\mathrm{Mg}$ containing small amounts of an HCP Ti-rich phase formed after milling for 48 and 72h, respectively at $800 \mathrm{rpm}$. An intermediate FCC solid solution of Ti in Mg was identified in powders milled for $24 \mathrm{~h}$ or less. The chemical composition of the matrix products extended from $\mathrm{Ti56}: \mathrm{Mg} 44$ to $\mathrm{Ti50}: \mathrm{Mg} 50$, which is close to the targeted equimolar ratio. XRD analysis of the structure suggested that the release of the lattice strain energy contributed to the driving force for transformation and solid solution between $\mathrm{Mg}$ and Ti after ball milling. Twinning was observed in Ti-rich crystallites at intermediate milling time. The twinning observed could be attributed to the deformation of Ti particles. However, in the Mg-Ti system, it might also indicate a strain induced martensitic transformation of the metastable $\omega$-FCC into BCC product. The crystallite boundaries acted as preferential sites for the heterogeneous nucleation of the twins and for the formation of solid solution by release of the lattice strain energy.
\end{abstract}

\title{
Graphical Abstract
}

\section{Summary}

Equimolar solid solution was achieved by means of ball milling of elemental $\mathrm{Mg}$ and Ti powders under Argon atmosphere in Simoloyer equipment. BCC and HCP products coexisted with amorphous material formed after $48 \mathrm{~h}$ milling. The driving force for solid solution was in part tribute of the release of the lattice strain energy. 
Twins have nucleated on crystallite boundaries and grew inside the Ti-rich crystallites after short milling time.

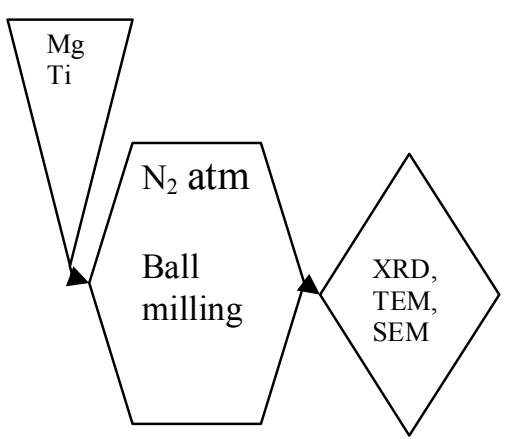

\section{Keywords}

Mg-Ti, solid solution, twinning, strain energy, microstructure, crystal structure

\section{Introduction}

Binary $\mathrm{Mg}_{\mathrm{x}}-\mathrm{Ti}_{(1-\mathrm{x})}$ systems are being investigated worldwide for electrochemical hydrogen storage applications [1-6]. Addition of Ti to Mg would improve the structural stability of a final $\mathrm{Mg}-\mathrm{Ti} \mathrm{BCC}$ (body-centered cubic) solid solution. It is expected that a final Mg-Ti alloy which would have a BCC structure will achieve higher hydrogen storage capacity than the close-packed FCC (face-centered cubic) and HCP (hexagonal close-packed) structures. However, the large difference in melting temperature between these two metals makes it difficult to synthesize such alloys by conventional casting routes. Mechanical alloying is an effective far-from equilibrium method capable of mixing even immiscible elements and extends their solid solubility, thus used to achieve solid solutions of Mg-Ti based system [1-14]. 
The microstructure and crystal structure of the alloy powders thus developed would be determinant in hydrogen storage capabilities.

Asano and his co-workers used a Fritsch P5 planetary ball mill to synthesize various chemistries of such Mg-Ti binary system using stainless steel or zirconia balls and milling pots. They have observed that the transformation from the initial HCP structures of elemental Ti and Mg into the HCP, FCC or BCC solid solutions of Ti in $\mathrm{Mg}$ were strongly determined by the mixed molar ratios of the two elements and by the dynamic energy which was dependent on the milling setup [1]. They observed that the crystal structure of $\mathrm{Mg}$-Ti was not affected by iron contamination (up to 5 at.\%) from the stainless steel balls and pots. Hence a BCC product could be formed in a stainless steel milling medium [2], whereas contamination by a zirconia milling medium was revealed to be detrimental to the formation of the BCC product [1]. Kalisvaart et al. [3] have investigated the effects of using graphite or stearic acid as a process control agent, in product structures in both low-energy (Uni-Ball-Mill II) and high-energy ball milling (Spex 8000-230) of Mg-Ti and Mg-Ti-Ni systems. From their work it was noted that the transformation from HCP to FCC structures during ball milling was related to a synergy between the process control agent, the impact generated by the milling balls and the dissolution of Ti in Mg. Sun and Froes [11] reported that the average grain size of the $\mathrm{Ti}-\mathrm{xMg}$ alloys decreased with increasing $\mathrm{Mg}$ content, whereas the volume fraction of grain boundaries significantly increased as the $\mathrm{Mg}$ content increased, suggesting that the grain boundary played an important role in enhancing the solid solubility of $\mathrm{Mg}$ in Ti. Repeated plastic deformation of raw materials was reported in the initial stage of the mechanical alloying of various metallic systems by ball milling. The critical resolved shear stress values (CRSS) at ambient temperatures of the basal plane slip system is about two orders of magnitude 
smaller than that of the prismatic plane slip system in $\mathrm{Mg}$ [15]. Hence Mg would be deformed mainly by basal plane slip during ball milling at ambient temperatures. In case of Ti however the value of the CRSS of the basal plane slip system is slightly larger than that of the prismatic plane system [15]. Ti would therefore be deformed by the twinning mechanism much more readily than $\mathrm{Mg}$ [16]. Other works showed that particle size is affected by the types and the amount of process control agent, and the milling duration [17-18].

Kalisvaart et al. [4] recently reported the formation of a mixture of two FCC compounds after milling of $\mathrm{Ti}-\mathrm{Mg}$ mixtures in the presence of a process control agent. Whereas HCP products with lattice constants $a=3.03 \AA$ and $c=4.84 \AA$ were obtained by solid solution of $\mathrm{Ti}$ in $\mathrm{Mg}$ when milling was undertaken in the absence of a process control agent using a coarse Mg powder particle size [5]. Previous work by Phasha et al. [13] showed that the milling speed and the starting average particle size ratio between $\mathrm{Mg}$ and $\mathrm{Ti}$ affected both the mechanism and the kinetics of solid solution during mechanical alloying. The authors observed that the mechanical alloying process was slowed and solid solution of $\mathrm{Ti}$ in $\mathrm{Mg}$ was difficult to achieve when the starting particle size of the soft $\mathrm{Mg}$ was 8 times larger than that of the hard $\mathrm{Ti}$. From the above studies it is inferred that the evolution of the structure of $\mathrm{Mg}-\mathrm{Ti}$ mechanical alloys is process dependent. Hence the evolution of both the microstructure and crystal structure of equimolar mixture of elemental $\mathrm{Ti}$ and $\mathrm{Mg}$ powders was investigated using SEM, XRD and TEM techniques to determine the onsets for formation and the distribution of new product phases with new crystal structures during ball milling at high rotation speeds in a Simoloyer roller ball mill. It is believed that the control of the crystal structure of the Mg-Ti milled product will determine the hydrogen storage performance of the mechanical alloy. 


\section{Experimental procedure}

Milling experiments were undertaken using a horizontal Simoloyer high energy ball mill whose milling chamber is static, whereas the milling balls are rolled at high speed by a series of large welded blades on a rotating shaft. Hence the mechanical energy is transferred from the shaft to the milling balls when impacted by the moving blades. The milling chamber is continuously cooled down by circulating water in a jacket. Elemental titanium powder ( $\sim 99.5 \%$ purity) and stabilised elemental magnesium powder ( $\sim 99.5 \%$ purity) were admixed manually to obtain $200 \mathrm{~g}$ of powder in the molar ratio $1: 1$. Stearic acid $(2 \mathrm{wt} \%)$ was added to the admixed powders as process control agent. The particle size analysis indicated that the starting elemental powders contained 50 weight percent (wt $\%$ ) of particles smaller than $27 \mu \mathrm{m}$ and $90 \mathrm{wt} \%$ of particles were smaller than $40 \mu \mathrm{m}$.

Pure titanium powder was first milled for $4 \mathrm{~h}$ to form a Ti-coating on the inner surface of the milling chamber and on the surface of the stainless steel balls. This helped preventing contamination of the milled powders by milling medium constituents. The powder mixture was then introduced into the milling chamber together with $2 \mathrm{~kg}$ of the $5 \mathrm{~mm}$ diameter Cr-stainless steel balls ( $\sim 0.5 \mathrm{~g}$ each) representing a 10:1 ball-topowder ratio. The milling chamber was then evacuated to $10^{-5}$ bar, before being filled with argon under 2 bars pressure. Continuous ball milling was conducted at $20^{\circ} \mathrm{C}$ for times varying from $1 \mathrm{~h}$ to $72 \mathrm{~h}$ at 400 rotations per minute (rpm) and $800 \mathrm{rpm}$. The mechanism of alloying was investigated by analysis of the crystal structure, the lattice strain and crystallite size determined by means of XRD and TEM techniques. $\mathrm{XRD}$ analysis were conducted using the $\mathrm{Cu} \mathrm{K}_{\alpha}$ radiation, $\lambda=0.15418 \mathrm{~nm}$. TEM analyses of the milled samples were also conducted under $200 \mathrm{kV}$ in a JEOL TEM. 
The chemistries of the phases formed during ball milling were determined by means of EDX technique. Samples for the SEM analysis were prepared by mounting the powder in a cold resin and then polished to observe their morphologies and distribution inside the cross section of the particles.

\section{Results and discussion}

\subsection{Microstructure evolution of the milled powder particles}

The commercial pure $\mathrm{Mg}$ and Ti powders used had quasi-circular cross sections as shown in Figure 1. Ti particles were spherical (light phase) while Mg particles were irregular (dark) in the backscattered electron SEM image. No chemical heterogeneity was observed in the cross sections of the initial powder particles. The shape, size and constituent distributions, and thus the homogeneity of the cross sections of the milled powder particles evolved thereafter as the milling time increased from $1 \mathrm{~h}$ to $72 \mathrm{~h}$. Three major changes could be observed in the morphologies of the particles, in Figure 2, as the milling time increased. Large lamellar structures of deformed $\mathrm{Mg}$ and $\mathrm{Ti}$ particles were formed at milling time comprised between $4 \mathrm{~h}$ and $8 \mathrm{~h}$. The lamellar structures were refined at intermediate milling time between $16 \mathrm{~h}$ and $24 \mathrm{~h}$. Solid solution has begun at these intermediate milling time at both $800 \mathrm{rpm}$ and $400 \mathrm{rpm}$ milling speed. Comparison between the evolution of microstructures and morphologies in Figure 2 and Figure 3 shows that the refinement of the lamellar microstructure was faster at higher milling speed $(800 \mathrm{rpm})$ than at $400 \mathrm{rpm}$. The refinement of the lamellar microstructure improved the kinetics of solubilisation of the two metals at higher milling speed. Fully homogeneous microstructures were achieved after $48 \mathrm{~h}$ milling at $800 \mathrm{rpm}$ whereas milling time of $72 \mathrm{~h}$ was needed to achieve similar results when milling was conducted at $400 \mathrm{rpm}$. 
The localised EDX analysis performed in 30 spots and areas in Figures $2 \mathrm{e}$ and $2 \mathrm{f}$ indicated that the compositions of the phases formed after $48 \mathrm{~h}$ and $72 \mathrm{~h}$ milling at 800 rpm ranged between Ti56:Mg44 to Ti50:Mg50. This confirmed the mechanicallyinduced solid solubilisation of an equimolar Ti-Mg system. The slight loss in magnesium $\sim 3$ at. $\%$ from the system might have occurred by mechanical drowning during the vacuuming stage of the chamber preceding the milling or by a preferential cold welding of $\mathrm{Mg}$ onto the surfaces of the milling balls and pots.

From the microstructures in Figures 2 and 3 it can be seen that milling of $\mathrm{Mg}$ and $\mathrm{Ti}$ mixtures at $400 \mathrm{rpm}$ by a Simoloyer ball mill yield the same intermediate as well as final products than milling at $800 \mathrm{rpm}$. However, the kinetics of refinement of the intermediate microstructure and the formation of the solid solution was faster at higher milling speed, which corresponds to the higher impact energy input in the milling process. Asano and his co-workers [1] found similar trends in Mg-Ti alloys processed in a Fritsch P5 planetary ball mill by varying the specific mass of the milling balls used at a constant milling speed of $200 \mathrm{rpm}$ and for substantially longer milling times.

\subsection{Crystal structure and phase analysis}

The X-ray spectra of the powders milled at $800 \mathrm{rpm}$ and $400 \mathrm{rpm}$ for different times are shown in Figure 4 and Figure 5, synthesized from previous work [13]. It inferred from Figure 4 that the $\mathrm{Mg}$ diffraction peaks were displaced toward higher angles and their intensities decreased more quickly than those of Ti as the milling duration increased. The Mg peaks (1) vanished completely after milling for $8 \mathrm{~h}$ at 800 rpm. Similar vanishing was observed after $24 \mathrm{~h}$ when the milling speed was $400 \mathrm{rpm}$ as seen in Figure 5. These XRD results suggest that $\mathrm{Mg}$ crystals were deformed first 
before dissolution of the $\mathrm{Ti}$ atoms in $\mathrm{Mg}$ took place. Indeed, the CRSS values at ambient temperatures are $0.5 \mathrm{MPa}$ for a basal plane slip system in $\mathrm{Mg}$ [15] and 140MPa for a twinning in $\mathrm{Ti}[16]$ which justify that $\mathrm{Mg}$ crystal readily deformed in the first stage of ball milling.

The Mg crystal structure was first strained and deformed in an HCP structure $\left(1^{\prime}\right)$ and later into a metastable $\omega$-FCC phase (3) which enabled significant dissolution of Ti in $\mathrm{Mg}$ as milling proceeded. The product of dissolution of Ti into the $\omega$-FCC phase had a BCC structure (5). The corresponding indexed electron diffraction patterns are shown in Figures 6 and 7. Indexing of the electron diffraction rings and the ratios of the ring diameters confirmed the presence of an intermediate FCC phase product formed after milling for $24 \mathrm{~h}$, whereas a final BCC phase was formed after $48 \mathrm{~h}-72 \mathrm{~h}$ milling. However, in both cases the electron diffraction rings were diffused indicating that the products of milling consisted of very fine crystallites highly strained or even could contain some amount of amorphized material.

$\mathrm{XRD}$ results in Figure 4 suggest that $\mathrm{Mg}$ atoms from the metastable $\omega$-FCC phase could also simultaneously have been dissolved into the strained HCP Ti lattice (2) to form a metastable HCP solid solution of Mg in $\mathrm{Ti}$ (4). Such metastable HCP solutions were reported by Asano et al. [1] in high titanium systems and by Rousselot et al. [5] at lower milling energy and shorter milling time.

The XRD patterns of the milled products obtained after milling for $48 \mathrm{~h}$ at speeds of $800 \mathrm{rpm}$ and $400 \mathrm{rpm}$ indicated that there was no significant structural difference between the two products formed.

Deformation twins were observed along the grain boundaries in some particles of powders milled for short time as shown in Figure 8. Twinning would normally be expected as the deformation mode in Ti particles, however it may also indicate a 
strain induced martensitic transformation of the metastable $\omega$-FCC into BCC product. The twins observed were smaller than $10 \mathrm{~nm}$ in both width and length. A more detailed analysis of these twins is still needed to determine the twinning planes, angles and ratios, hence their formation mechanism. It infers from Figure 8 that the twins grew from the crystallite boundaries which acted as preferential sites for their heterogeneous nucleation. This confirms the role played by the boundaries in the process of storing and releasing the crystal lattice strain energy, thus in the kinetics of formation of the solid solution during ball milling of the Ti-Mg mixtures. Similar role of the grain boundaries was pointed out by Sun and Froes [11] in their work on the mechanical alloying of Ti-xMg mixtures.

The effects of milling speed and time, hence the energy input, on the crystal lattice strains of $\mathrm{Mg}$, $\mathrm{Ti}$ and their respective solid solutions were investigated by separation of the crystallite size $L$ and the strain $e$ carried out by means of the Williamson-Hall method.

$$
\delta(2 \theta) \cos \theta=\frac{\lambda}{L}+4 e \sin \theta
$$

$\theta$ and $\delta(2 \theta)$ in Equation (1) are the diffraction angle and the corresponding full width at half-maximum (FWHM) of the peak. The lattice strains $e$ of the obtained products increased as the milling time increased at both milling speeds and the trends are schematically illustrated in Figure 9, which shows non-monotonic evolutions. It is noted in this figure that the lattice strains $e$ of Ti and the deformed $\mathrm{Ti}$ (curve A) as well as $\mathrm{Mg}$ and the solid solutions of $\mathrm{Ti}$ in $\mathrm{Mg}$ (curve $\mathrm{B}$ ) increased to local maxima after milling for $4 \mathrm{~h}$ at $800 \mathrm{rpm}$ or after $8 \mathrm{~h}$ when milling speed were $400 \mathrm{rpm}$. The lattice strains decreased after these maxima prior to other increases and decreases occurring at longer milling times. Comparison of these lattice strains to the SEM and 
TEM results leads to the following remarks on the evolution of the microstructure and crystal structure of the equimolar Mg:Ti mixture during high energy ball milling at 800 rpm:

- Stage 1, the HCP crystal lattices of both magnesium (1) and titanium (2) are deformed, resulting in increased lattice strains in the powders milled for $4 \mathrm{~h}$. The increase in lattice strains led to the formation of the deformed hcp transitional phases (1) in $\mathrm{Mg}$ and (2) in $\mathrm{Ti}$.

- Stage 2, Ti is dissolved into the deformed Mg lattice (1) to form a metastable $\omega$-FCC solid solution (3) which coexisted with an hcp solution of Mg into Ti (4). The sharp drop in lattice strain in both (curve A) and (curve B) to lower at $8 \mathrm{~h}-16 \mathrm{~h}$ milling time in figure 9 , suggests that at least part of the lattice strain energy released drove the solid solution of $\mathrm{Ti}$ in $\mathrm{Mg}$ to form the fcc solid solution (3).

- Stage 3, the crystal lattices of the Mg-rich matrix phase (4) and the Ti-rich HCP (2') are heavily deformed after milling for more than $24 \mathrm{~h}$ at $800 \mathrm{rpm}$. This led to a second stage of increase in lattice strain energies in both the transitional $\omega$-FCC phase (3) and the HCP (2) prior to another release which drove the formation of the final BCC phase (5).

Asano et al. [1] reported the formation of a similar BCC phase after milling of an equimolar $\mathrm{Ti}-\mathrm{Mg}$ mixture for $150 \mathrm{~h}$ in a planetary ball mill at a lower rotation speed, i.e. $200 \mathrm{rpm}$.

It was pointed out in this study that the kinetics of transformation of the crystal structures was slower in the products milled at $400 \mathrm{rpm}$. Products having similar structures to those achieved after $8 \mathrm{~h}$ milling at $800 \mathrm{rpm}$ were only formed after $24 \mathrm{~h}$ milling at $400 \mathrm{rpm}$. The longer milling time products, however, contained an FCC 
solid solution of $\mathrm{Ti}$ in $\mathrm{Mg}$, but no undissolved $\mathrm{Ti}$. This suggested that milling at moderate rotation speed could enhance the dissolution of Ti into $\mathrm{Mg}$ by lowering the strain, thus the density of dislocations which hindered the movement of Ti atoms necessary to the formation of a solution of $\mathrm{Ti}$ in $\mathrm{Mg}$.

The crystallite sizes of $\mathrm{Mg}$ and solid solutions of $\mathrm{Ti}$ in $\mathrm{Mg}$ (curves $\mathrm{B}$ ) and those of $\mathrm{Ti}$ and deformed $\mathrm{Ti}$ (curves A) are presented in Figure 10 as milling time increases. It resorts from these curves that the crystallites of all the phases in the starting materials were refined during the first $4 \mathrm{~h}$ of milling before solid solution process starts. The formation of metastable $\omega$-FCC solid solutions corresponds to the increase in crystallite size between $4 \mathrm{~h}-8 \mathrm{~h}$ and between $8 \mathrm{~h}-16 \mathrm{~h}$ at $800 \mathrm{rpm}$ and $400 \mathrm{rpm}$ milling speeds respectively. In general the crystallites of both $\mathrm{Ti}$ and $\mathrm{Mg}$ and those of the phases formed during ball milling were finer at lower milling speed (400 rpm) than in the case of $800 \mathrm{rpm}$ until milling time became longer than $48 \mathrm{~h}$. The crystallite sizes of the products were similar in materials milled for more than $48 \mathrm{~h}$. The larger size of the crystallites formed and the faster kinetics of dissolution $\mathrm{Ti}$ in $\mathrm{Mg}$ at the higher milling speed may be attributed to an intense cold welding due to a higher impact energy input which also enhanced the diffusion rates of the atoms across the interfaces between welded powder particles and the subsequent expansion of the crystal lattice of $\mathrm{Mg}$ in powder particles previously compressed and deformed when impacted in between high energy balls. A summary of the dominant processes taking place during ball milling of $\mathrm{Mg}$ and Ti powders is presented in Table 1. It appears from the above observation that the crystal structure of the product obtained by high energy ball milling of equimolar Ti-Mg mixtures depends on the energy input, which is a function of the rotation speed, the mass of the balls and the milling time. This may explain the 
variety of crystal structures reported in the literature for the Ti-Mg systems and their dependence on milling [1-9, 11-14].

\section{Conclusion}

The solid solubility of the $50-50$ at. $\%$ Ti-Mg by means of high energy ball milling was achieved using a Simoloyer type high energy ball mill. The spot EDX analysis revealed that the chemical composition of the final solid solutions in products milled for 48 - 72h varied from Ti56:Mg44 to Ti50:Mg50, which is very close to the initial equimolar composition of the powders mixtures and the targeted Ti50:Mg50.

Both XRD and TEM techniques revealed the existence of a metastable FCC and BCC solid solution of $\mathrm{Ti}$ in $\mathrm{Mg}$ together with traces of $\mathrm{HCP}$ Ti-rich phase in materials milled for $24-48 \mathrm{~h}$ and $72 \mathrm{~h}$, respectively at $800 \mathrm{rpm}$. The formation of a metastable $\omega$-FCC phase was observed at intermediate milling time between 4 and $24 \mathrm{~h}$. The formation of the metastable transitional $\omega$-FCC phase enhanced the dissolution of Ti into Mg. The transformation from HCP-FCC-BCC structure is attributed to slip of the basal plane in magnesium.

The comparison of the change in lattice strains and the sequence of change in microstructure suggests that the release of the lattice strain energy in both the Mg-rich matrix and the Ti-rich phase drove the phase transformations and contributed to the driving force for solid solution in the Ti:Mg system.

The crystallite sizes of the products formed at higher milling speed were larger than those formed at lower milling speed. However, the kinetics of alloying by solid solution was enhanced in powder particles milled at the higher speed. Twins were observed along the grain boundaries in some particles of powders milled for short time. The twinning observed could be attributed to the deformation of $\mathrm{Ti}$ 
particles. However, in the Mg-Ti system, it might also indicate a strain induced martensitic transformation of the metastable $\omega$-FCC into BCC product. The crystallite boundaries acted as preferential sites for the heterogeneous nucleation of the twins.

\section{Acknowledgements}

This work was supported by the Department of Science and Technology (DST) of South Africa and the Council for Scientific and Industrial Research (CSIR), division of Materials Science and Manufacturing (MSM) in the Metals and Metals Processing (MMP) unit. The authors are thankful toward Dr David Whitefield for proofreading and editing the text of this paper.

\section{References}

1. K. Asano, H. Enoki, E. Akiba, Synthesis of hep, fcc and bec structure alloys in Mg-Ti binary system by means of ball-milling, J. Alloys Compd. 480 (2009) $558-563$

2. K. Asano, H. Enoki, E. Akiba, Synthesis process of Mg-Ti BCC alloys by means of ball milling, J. Alloys Compd. 486 (2009) 115-123

3. W.P. Kalisvaart, P.H.L. Notten, Mechanical alloying and electrochemical hydrogen storage of Mg-based systems, J. Mater. Res. 23 (8) (2008) 21792187

4. H. Huang, K. Huang, S. Liu, D. Chen, Microstructures and electrochemical properties of $\mathrm{Mg}_{0.9} \mathrm{Ti}_{0.1} \mathrm{Ni}_{1-\mathrm{x}} \mathrm{M}_{\mathrm{x}}(\mathrm{M}=\mathrm{Co}, \mathrm{Mn} ; x=0,0.1,0.2)$ hydrogen storage alloys, Powder Technol. (2009), doi:1016/j.powtec.2009.11.003

5. W.P. Kalisvaart, H.J. Wondergem, F. Bakker, P.H.L. Notten, Mg-Ti based materials for electrochemical hydrogen storage, J. Mater. Res. 22 (6) 2007 
6. S. Rousselot, M.P. Bichat, D. Guay, L. Roué, Structure and electrochemical behaviour of metastable Mg50Ti50 alloy prepared by ball milling, J. Power Sources 175 (2008) 621-624

7. R. Sundaresan, F.H. Froes, Mechanical alloying in the titanium-magnesium system, Key Eng. Mater. 29-31 (1988) 199-206

8. Enhong Zhou, C. Suryanarayana, F.H. (Sam) Froes, Effect of premilling elemental powders on solid solubility extension of magnesium in titanium by mechanical alloying, Mater. Lett. 23 (1995) 27-31

9. D.M.J. Wilkes, P.S. Goodwin, C.M. Ward-Close, K. Bagnall, J. Steeds, Solid solution of Mg in Ti by mechanical alloying, Mater. Lett. 27 (1996) 47-52

10. O.N. Senkov, M. Cavusoglu, F.H. (Sam) Froes, Synthesis of a low-density TiMg-Si alloy, J. Alloys Compd. 297 (2000) 246-252

11. F. Sun, F.H. (Sam) Froes, Synthesis and characterization of mechanical alloyed Ti-xMg alloys, J. Alloys Compd. 340 (2002) 220-225

12. G. Liang, R. Schulz, Synthesis of Mg-Ti alloy by mechanical alloying, J. Mater. Sci. 38 (2003) 1179-1184

13. M. Phasha, K. Maweja, C. Babst, Mechanical alloying by ball milling of Ti and Mg elemental powders: Operation condition considerations, J. Alloys Compd., doi:10.1016/j.jallcom.2009.11.184

14. C. Suryanarayana, F.H. Froes, Nanocrystalline titanium-magnesium alloys through mechanical alloying, J. Mater. Res. 5 (1990) 1880-1886

15. H. Tonda, S. Ando, Effect of temperature and shear direction on yield stress by $\{112-2\}<1123>$ slip in HCP metals, Metall. Mater. Trans. A 33 (2002) $831-836$ 
16. M.H. Yoo, Slip, twinning and fracture in hexagonal close-packed metals, Metall. Trans. A 12 (1981) 409-418

17. Y.F. Zhang, L. Lu, S.M. Yap, Prediction of the amount of PCA for mechanical milling, Materials Processing Technology 89-90 (1999) 260-265

18. J-S. Byun, J-H. Shim, Y.W. Cho, Influence of stearic acid on mechanochemical reaction between Ti and BN powders, J. Alloys Compd. 365 (2004) 149-156 


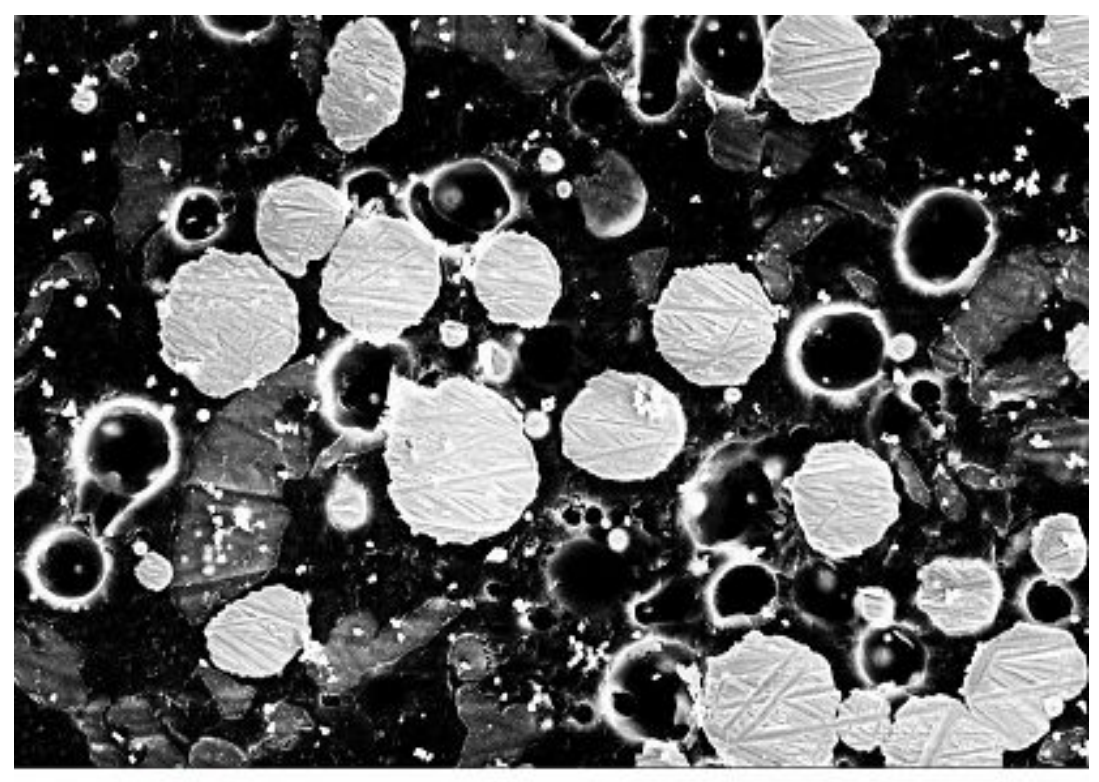

$\longmapsto 20 \mu \mathrm{m}$

Figure 1: BSE-SEM of the cross sections of the powders particles before milling.

Titanium bright areas and magnesium gray areas. Resin black areas. 

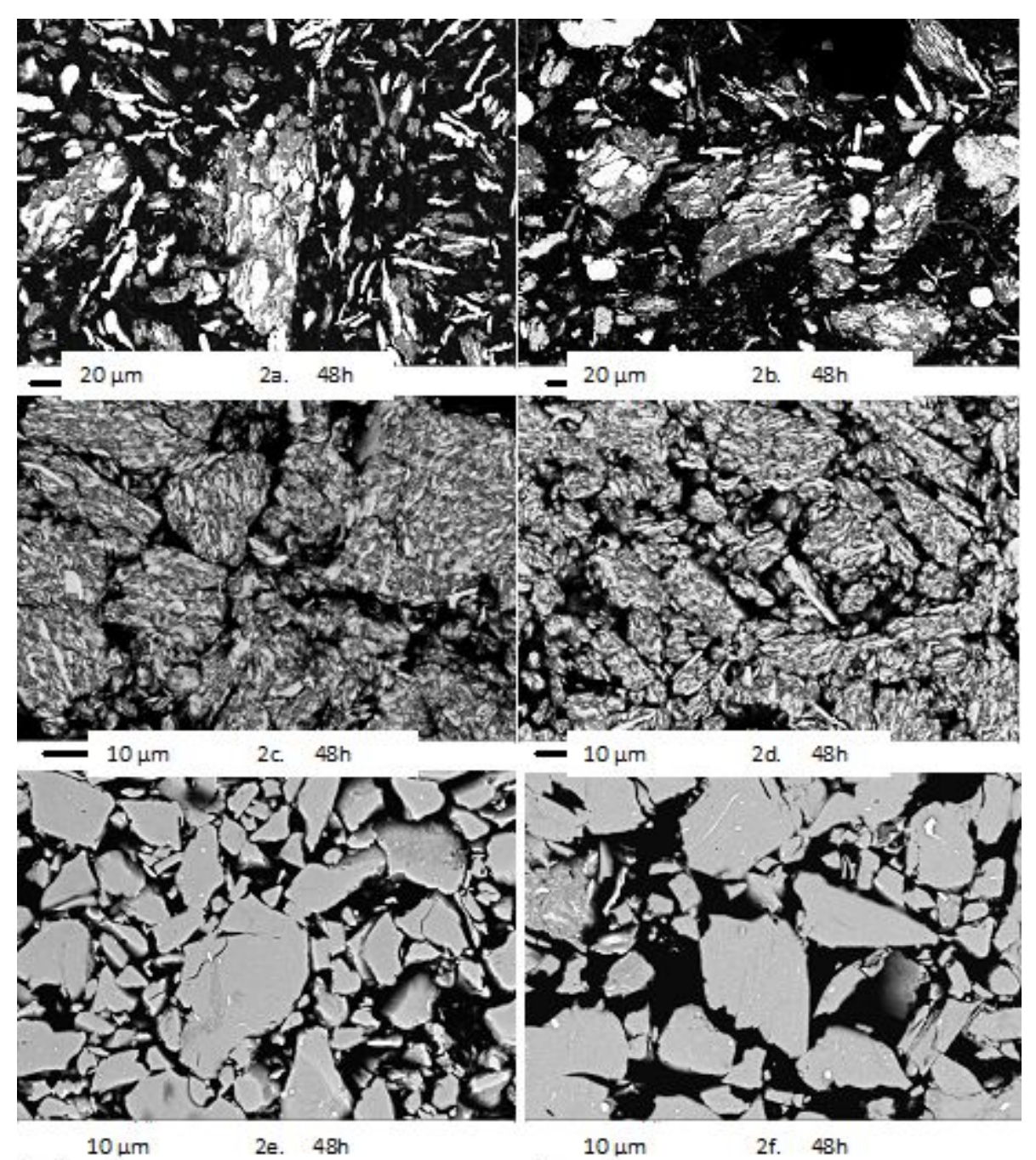

Figure 2: BSE-SEM showing the evolution of the morphology and microstructure of the powder mixture with milling time at $800 \mathrm{rpm}$ 

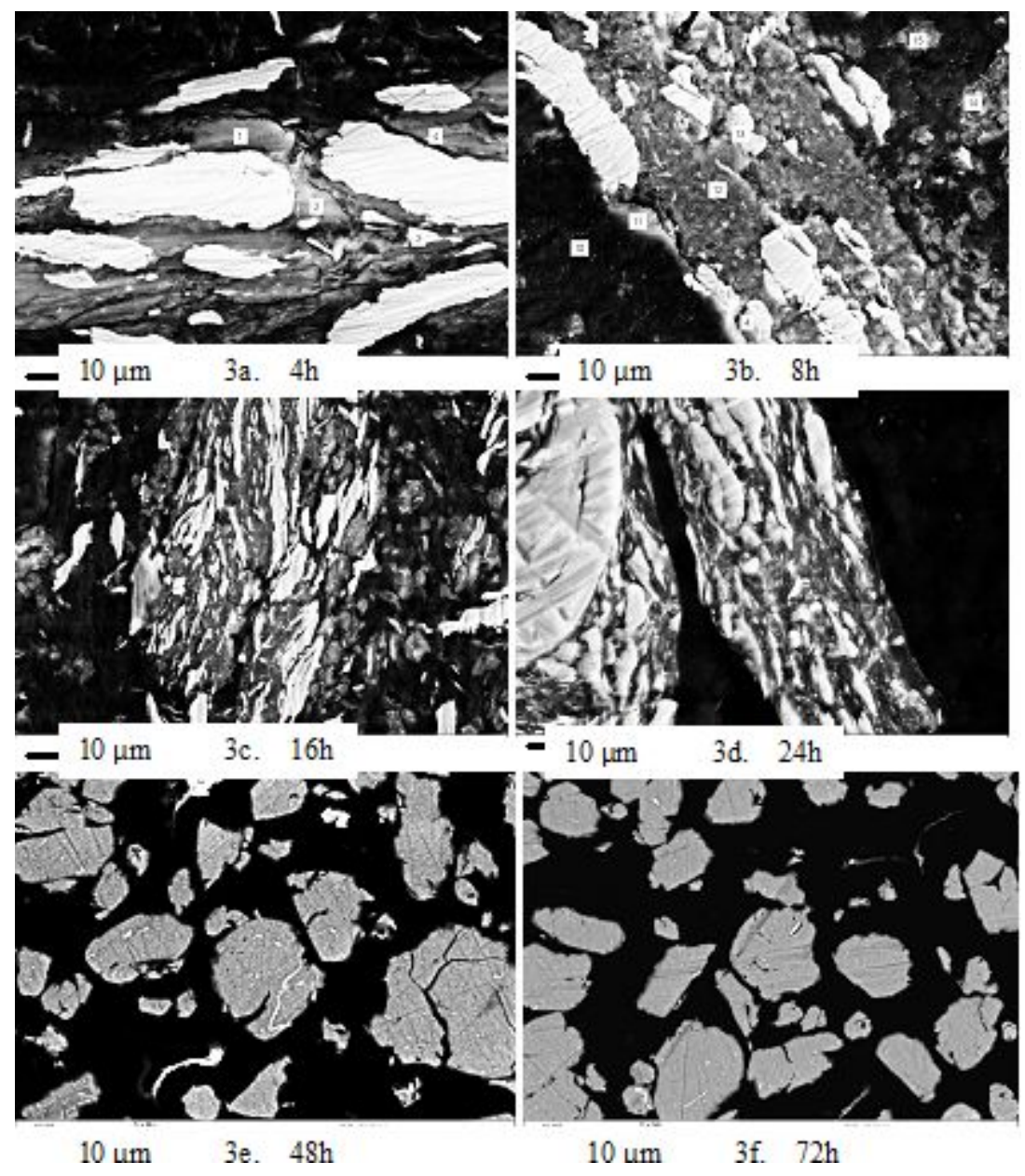

Figure 3: Evolution of the morphology and microstructure of powder mixtures with milling time at $400 \mathrm{rpm}$. 


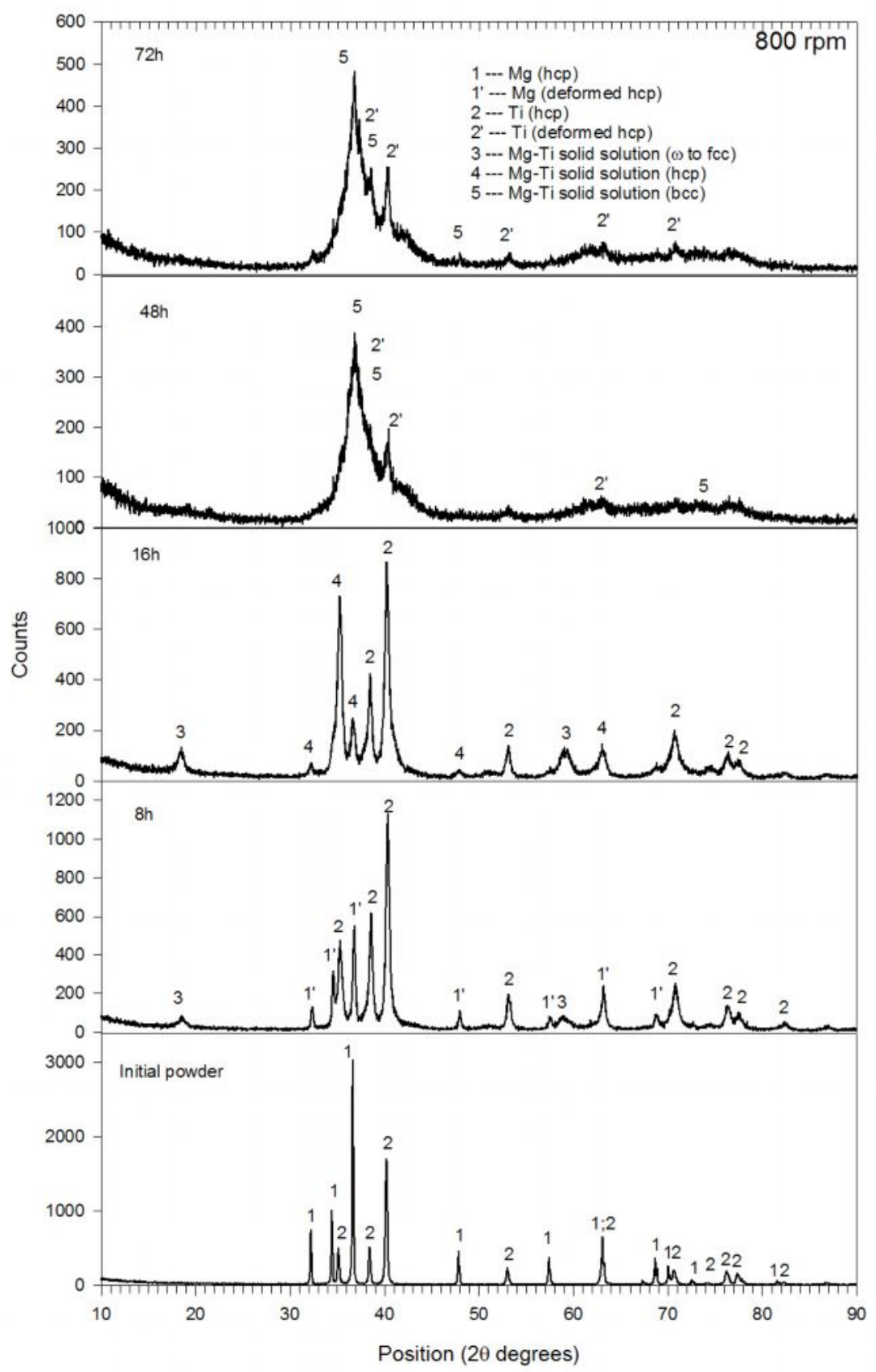

Figure 4: XRD patterns of powders milled for different time at $800 \mathrm{rpm}$ (synthesized from the previous work [13]) 


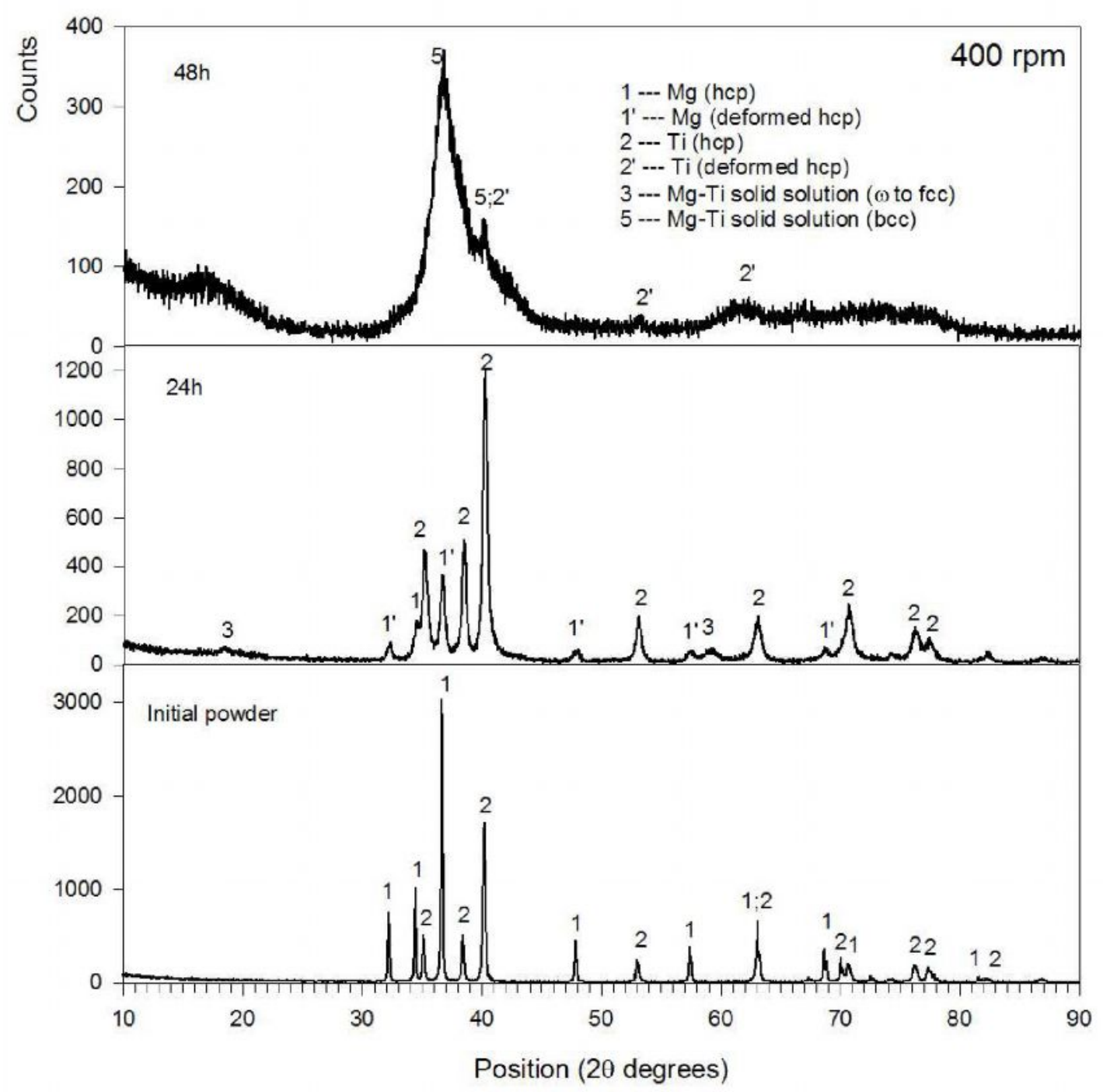

Figure 5: XRD patterns of powders milled for different time at $400 \mathrm{rpm}$ (synthesized from the previous work [13]) 


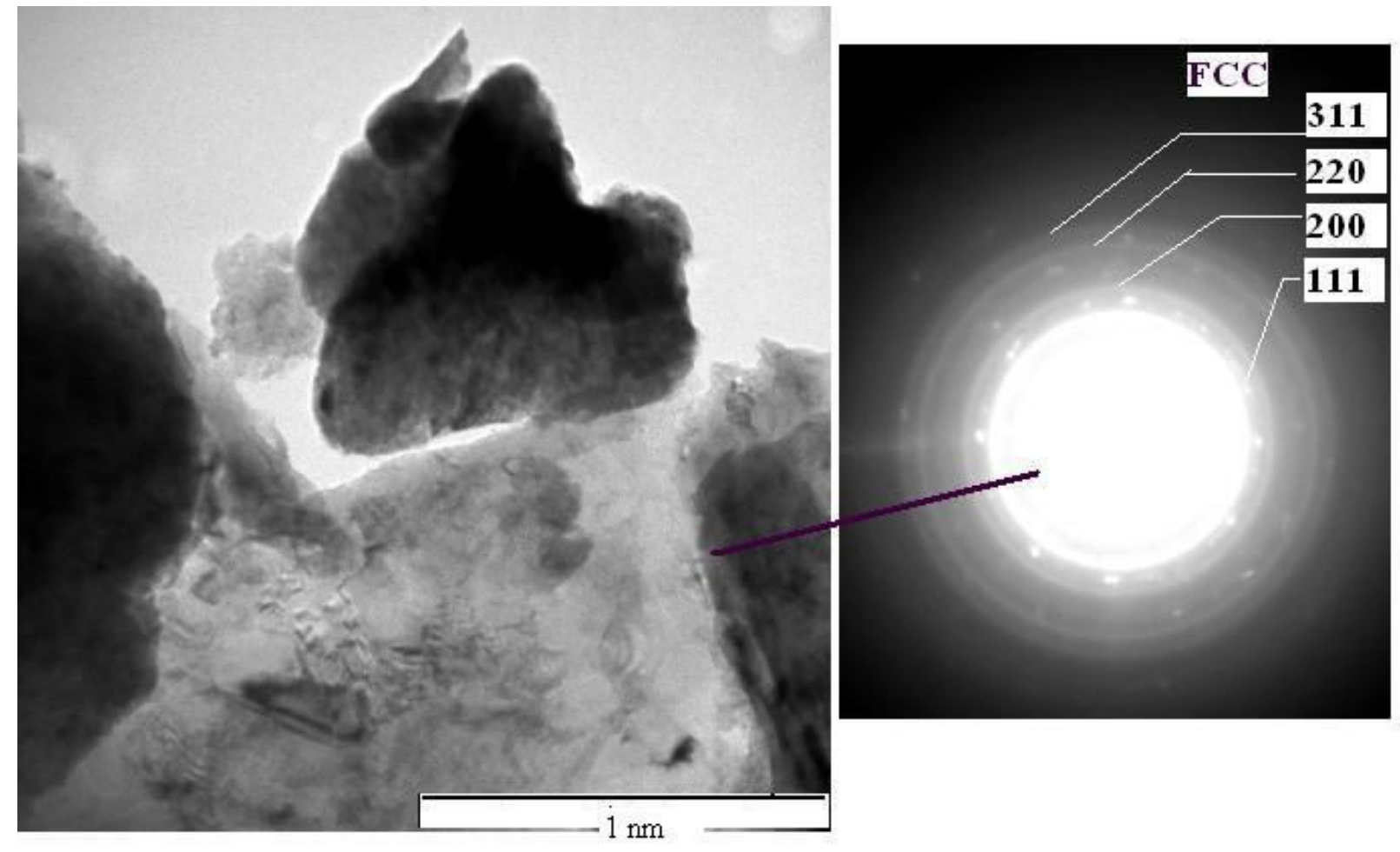

Figure 6: TEM image and the corresponding SADP illustrating the diffused rings of fine crystallite of an FCC phase in powders milled for $24 \mathrm{~h}$ at $800 \mathrm{rpm}$ 

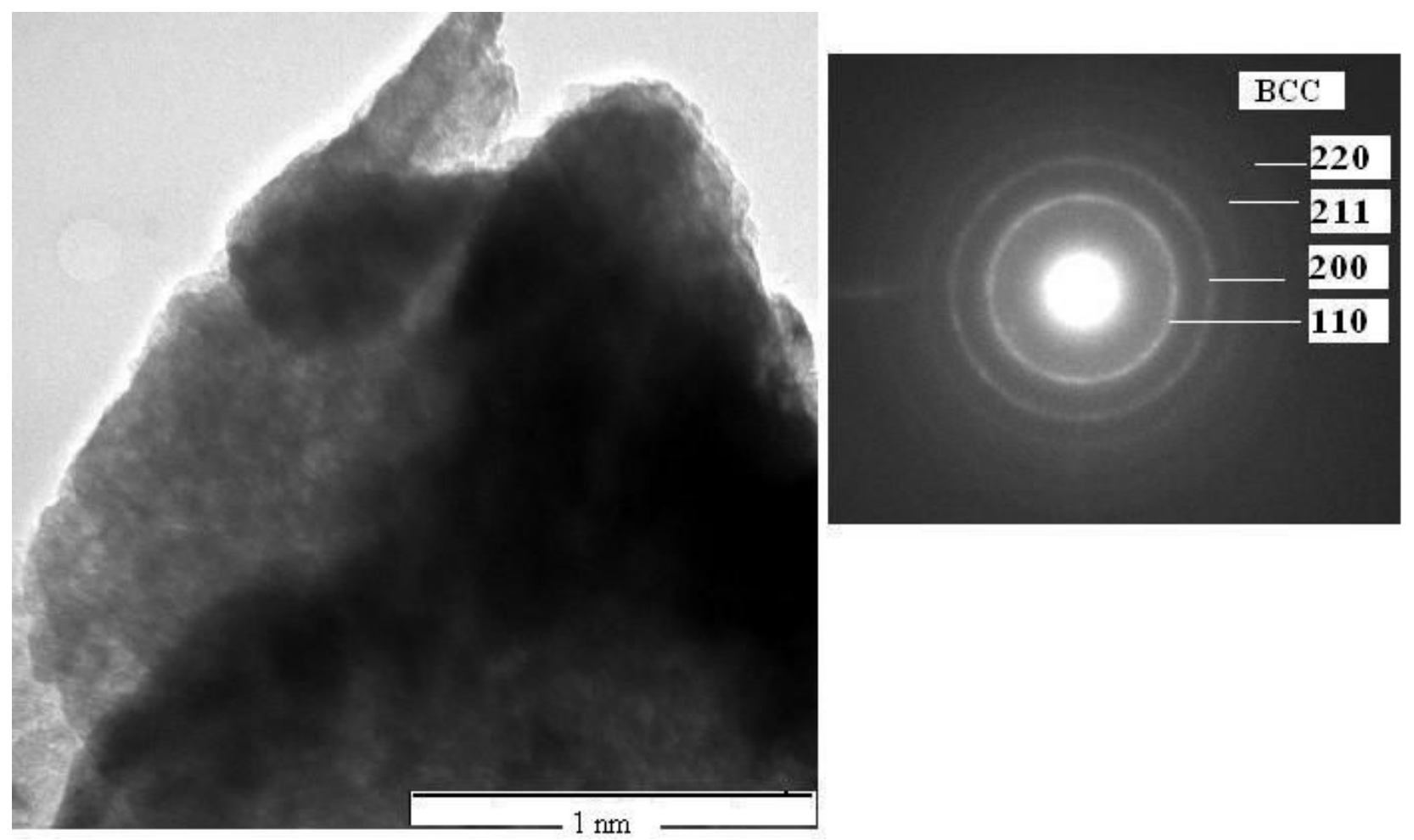

Figure 7: Typical TEM image of the products milled for $72 \mathrm{~h}$ at $800 \mathrm{rpm}$ and the corresponding SADP showing the diffused rings of fine crystallites of a BCC product 


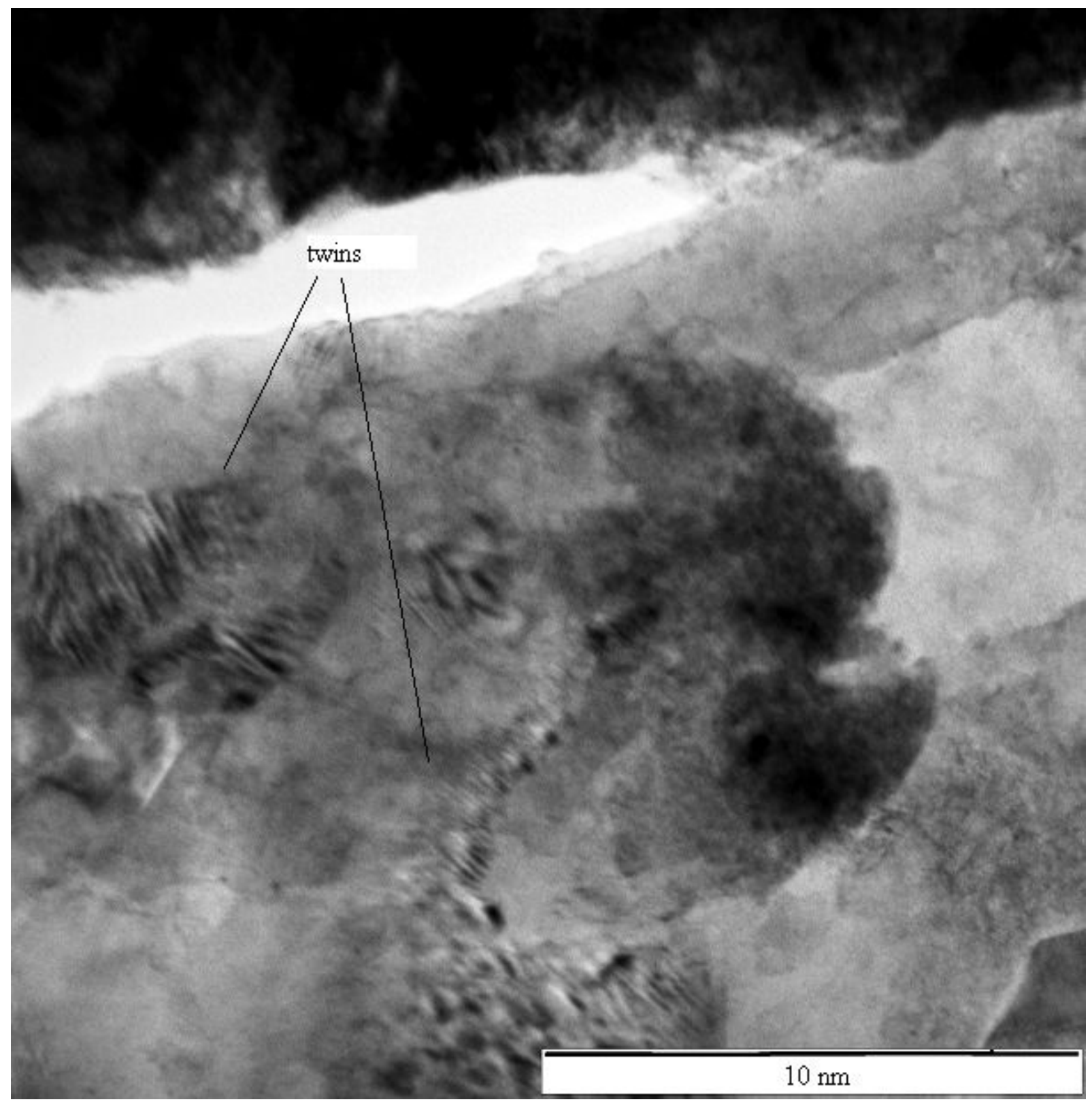

Figure 8: TEM image showing the twins formed along the boundaries in some areas of the powders milled for $24 \mathrm{~h}$ at $800 \mathrm{rpm}$ at room temperature 


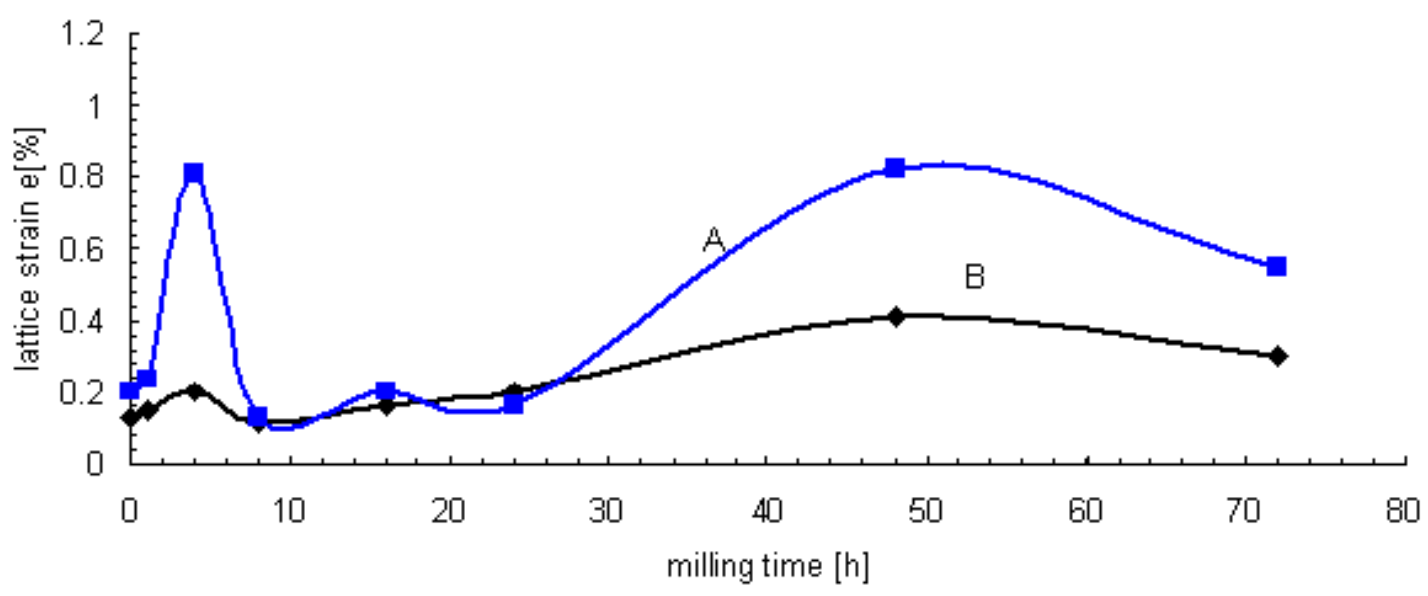

$400 \mathrm{rpm}$

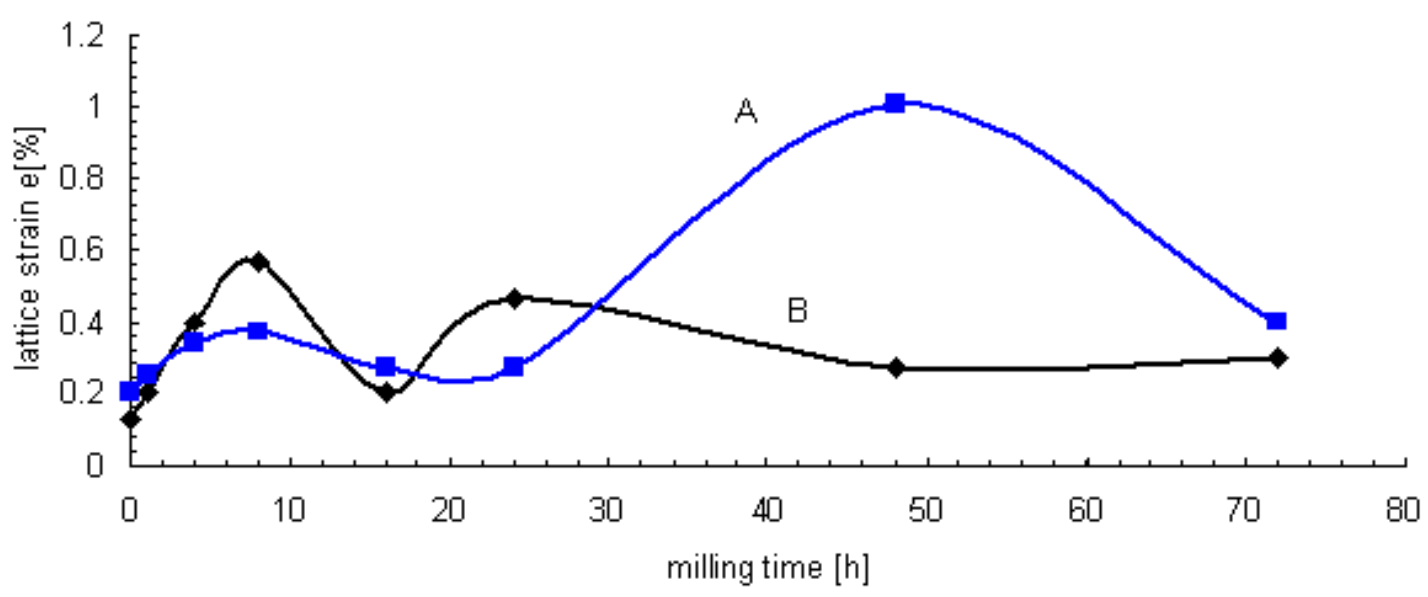

Figure 9: Evolution of calculated crystal lattice strains of products after milling at 400 rpm and 800 rpm versus milling time. (Curve $\mathrm{A}=\mathrm{Ti}$ and deformed $\mathrm{Ti}$, Curve $\mathrm{B}=\mathrm{Mg}$ and solid solution of $\mathrm{Ti}$ in $\mathrm{Mg}$ ) 


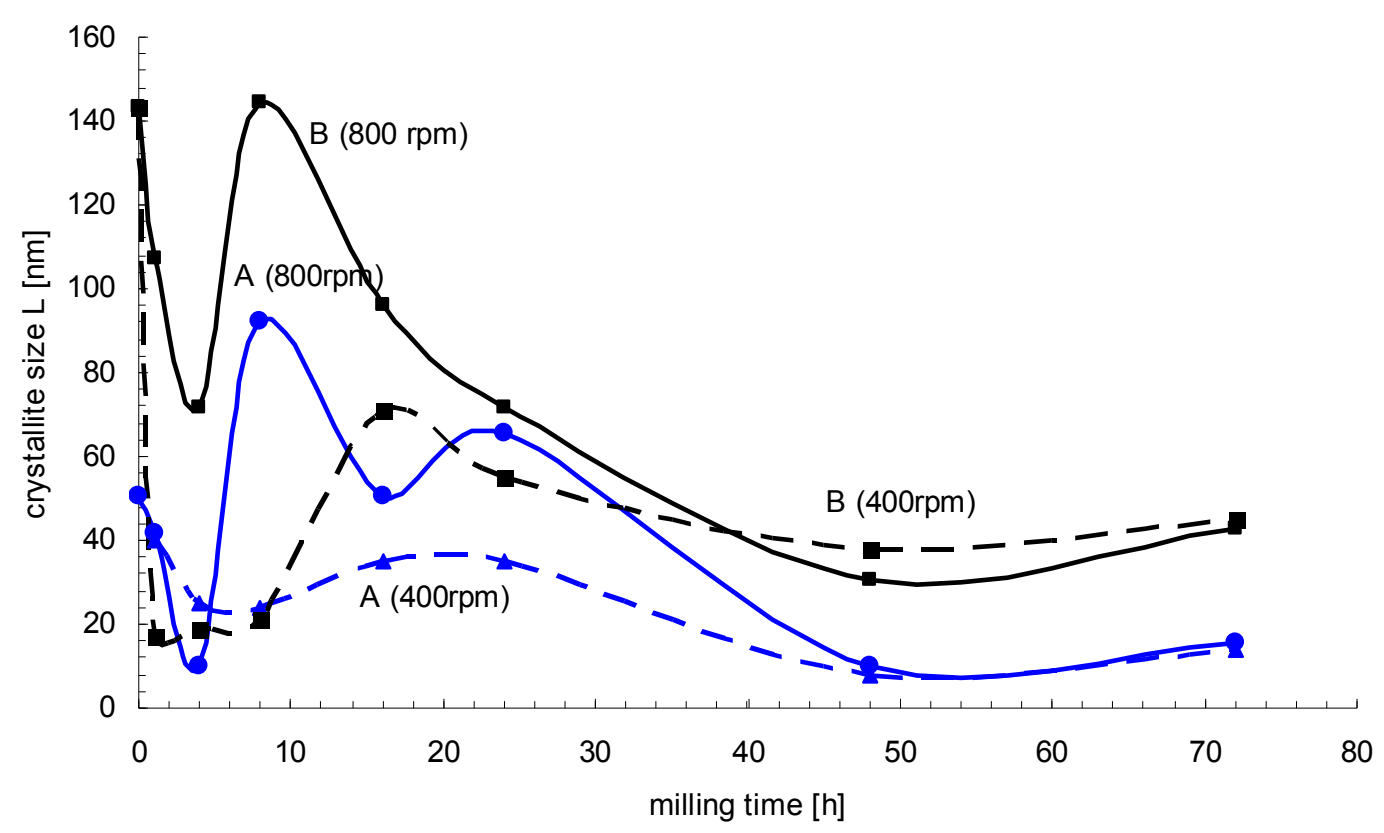

Figure 10: Crystallite sizes of products formed at various milling times and milling speeds (400 rpm (dashed line) and $800 \mathrm{rpm}$ (solid line)). (Curves A = Ti and deformed $\mathrm{Ti}$, Curves $\mathrm{B}=\mathrm{Mg}$ and solid solution of $\mathrm{Ti}$ in $\mathrm{Mg}$ ) 
Table 1. Dominant processes occurring with respect to crystallite size and solution during ball milling of Mg and Ti powders by a Simoloyer

\begin{tabular}{|c|c|c|c|c|c|c|}
\hline $\begin{array}{l}\text { Milling } \\
\text { speed }\end{array}$ & $1 h-4 h$ & $>4 h-8 h$ & $>8-16 h$ & $>16-24 h$ & $>24 h-48 h$ & $>48 h-72 h$ \\
\hline 400 rpm & Refinement & Refinement & $\begin{array}{l}\text { Expansion. Cold welding. Strain } \\
\text { energy release. Solid solution. } \\
\omega \text {-FCC product }\end{array}$ & Refinement & Refinement & $\begin{array}{l}\text { Insignificant } \\
\text { change in } \\
\text { crystallite size. } \\
\text { BCC product }\end{array}$ \\
\hline 800 rpm & Refinement & $\begin{array}{l}\text { Expansion. Cold welding. Strain } \\
\text { energy released. Solid solution. } \\
\omega \text {-FCC product }\end{array}$ & Refinement & $\begin{array}{l}\text { Refinement of Mg- } \\
\text { rich crystallites. } \\
\text { Cold welding of Ti- } \\
\text { rich crystallites }\end{array}$ & Refinement & $\begin{array}{l}\text { Insignificant } \\
\text { change in } \\
\text { crystallite size.. } \\
\text { BCC product }\end{array}$ \\
\hline
\end{tabular}

